دراسة التركيب المجهري وبعض الخواص الميكانيكية للمواد المتراكبة ذات اساس

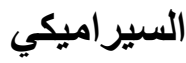

سالم عزيز كاكو/مدرس مساعد /المعهذ الفني اربيل

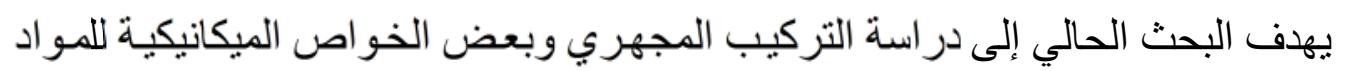

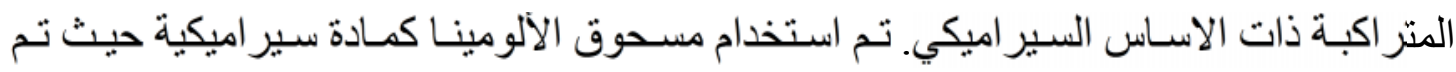

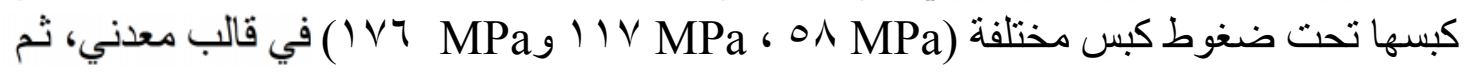

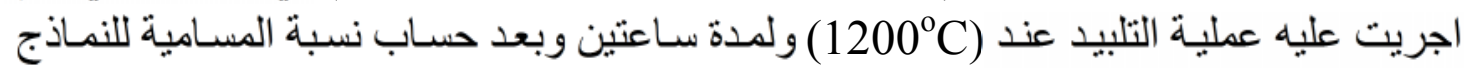

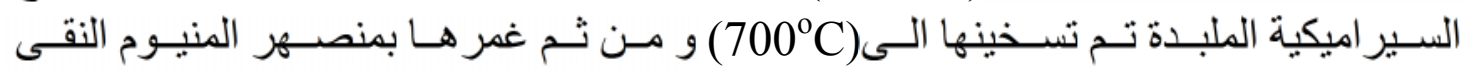

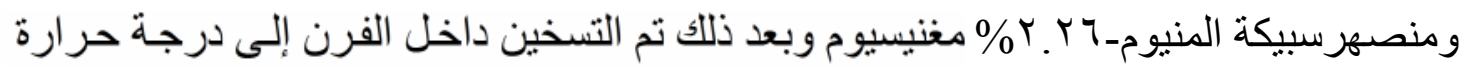
(1000 C)

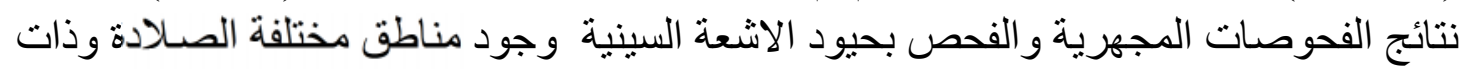

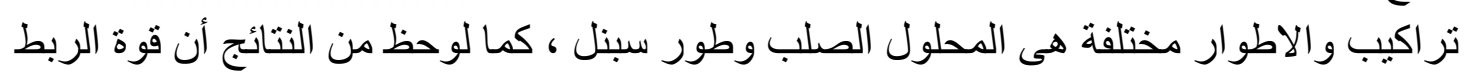

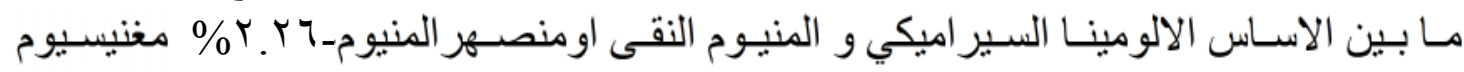

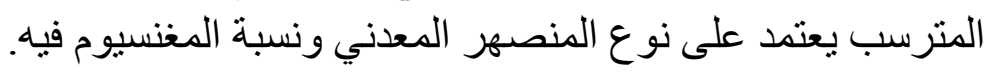

\title{
Study of Microstructure and Some Mechanical \\ Properties of Ceramic Matrix Composite Material
}

Salim Aziz Kako / Assist. Lecturer /Erbil Technical Institute

\begin{abstract}
The aim of this research is to study microstructure and some mechanical properties of ceramic matrix composite material. Powder of $\mathrm{Al}_{2} \mathrm{O}_{3}$ was used as ceramic material after had been pressed by different pressures (58 Mpa, $117 \mathrm{Mpa}$ and $176 \mathrm{Mpa}$ ) in metallic mold. The
\end{abstract}


sintering process has been preformed at $1200^{\circ} \mathrm{C}$ for two hours. After that, the porosity percentage has been measured and the samples were heated to $700^{\circ} \mathrm{C}$ and then immersed in the molten pure aluminum and (Al-2.26\% $\mathrm{Mg}$ ), and heated to about $1000^{\circ} \mathrm{C}$ for half an hour. Then, the samples were cooled to $650^{\circ} \mathrm{C}$. Microscopic tests and x-ray diffraction analysis has revealed zones with different hardness and with different structures. Moreover, the results showed that the adhesion between the ceramic matrix and the deposited metal depends on the molten metal type and the percentage of magnesium content of aluminum.

Keywords: Composites, Ceramic-metal bonding, Infiltration

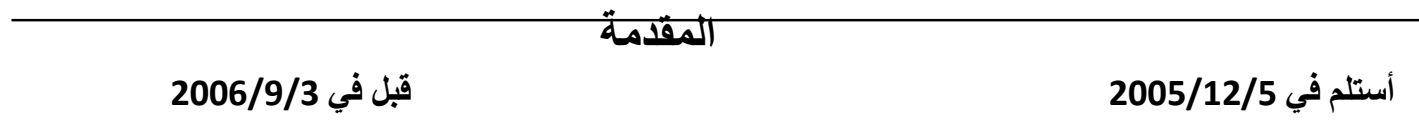

تعرف المو اد المتر اكبة (Composite material ) بانها المو اد التي تتكون من مادتين

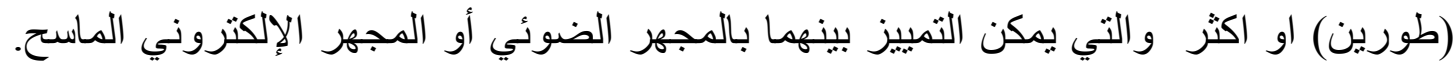

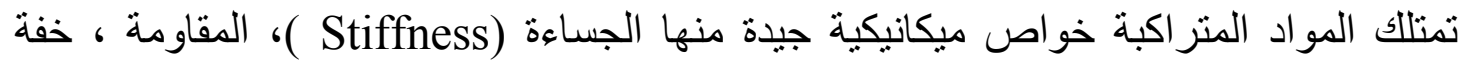

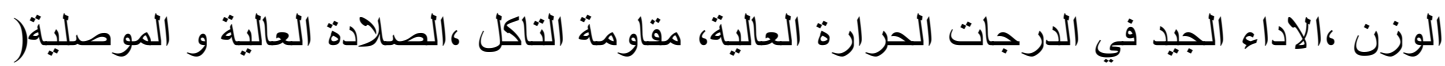
(Conductivity

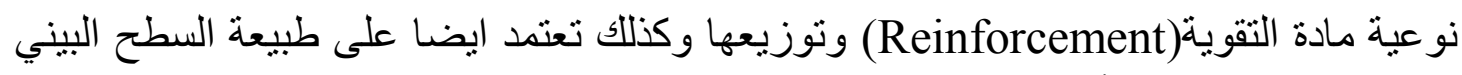
(Interface)

ويمكن تصنيف المو اد المتر اكبة اعتماداً على نوعية مادة الاساس الى : [4]

• مو اد متر اكبة ذات أساس بوليميري. Polymer Matrix Composites Metal Matrix Composites

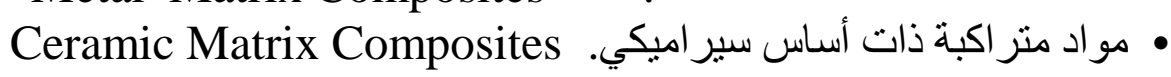

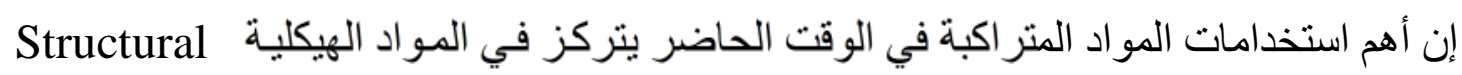

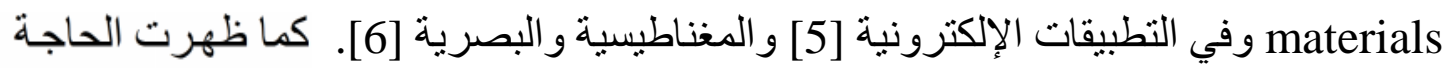

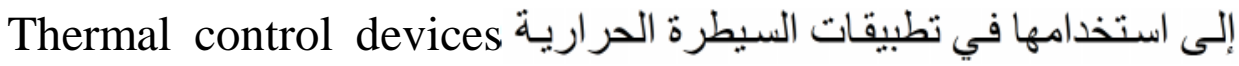


الإلكترونية Electronic packaging [7].ان الايفاء بمنطلبات هذه التطبيقات يتطلب استخدام

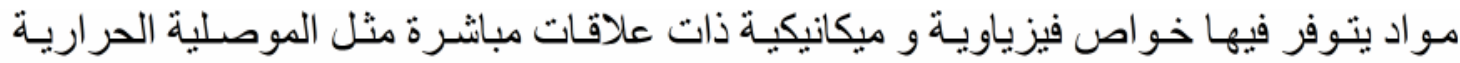

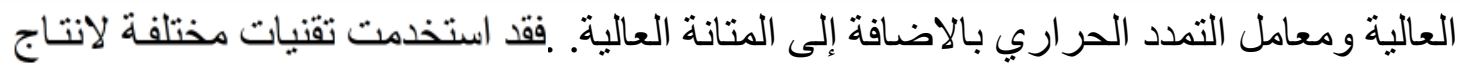

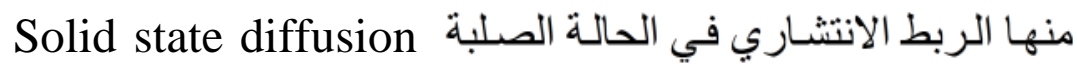

.] Resin bonding

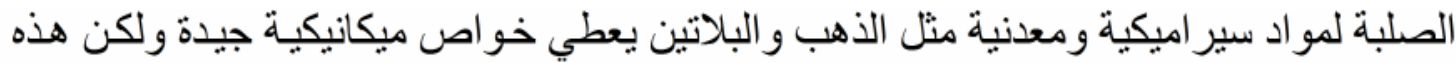

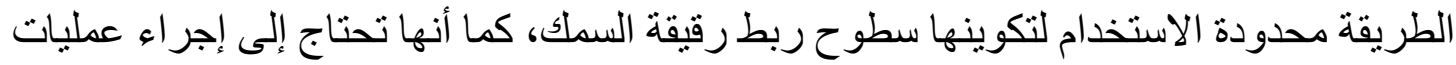

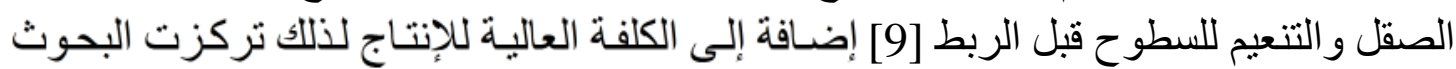

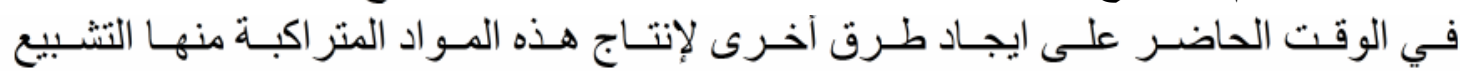
Infiltration

طرائق العمل و المواد المستخدمة: Materials Used and Procedure Methods

1 - مسحوق أوكسيد الألمنيوم (الألومينا)

استخدم مسحوق الألومينا

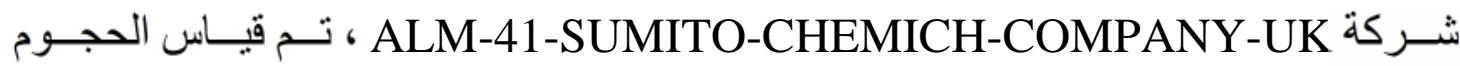

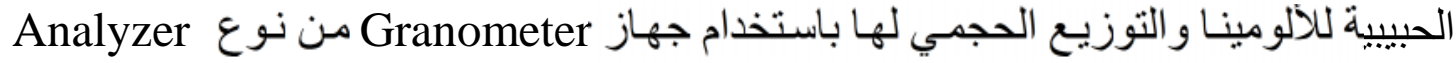

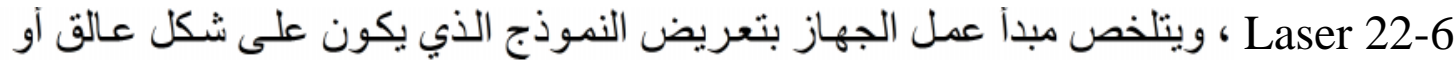

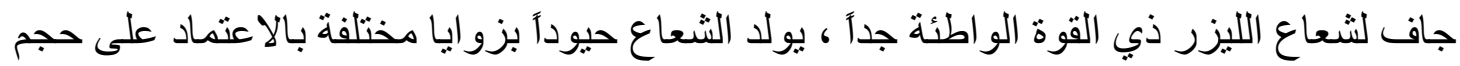

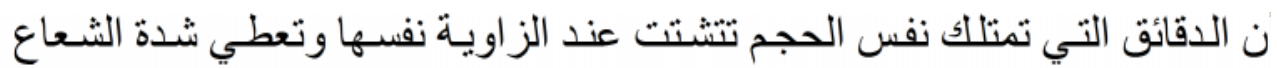

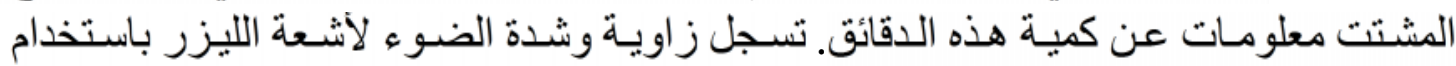

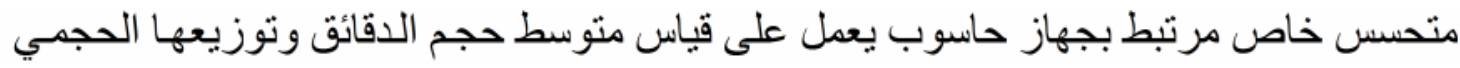

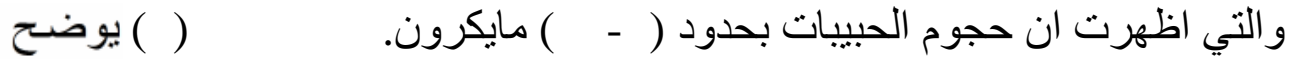
نتائج فحص حيود الأشعة السينية لمسحوق الألو مينا المستخدم. 


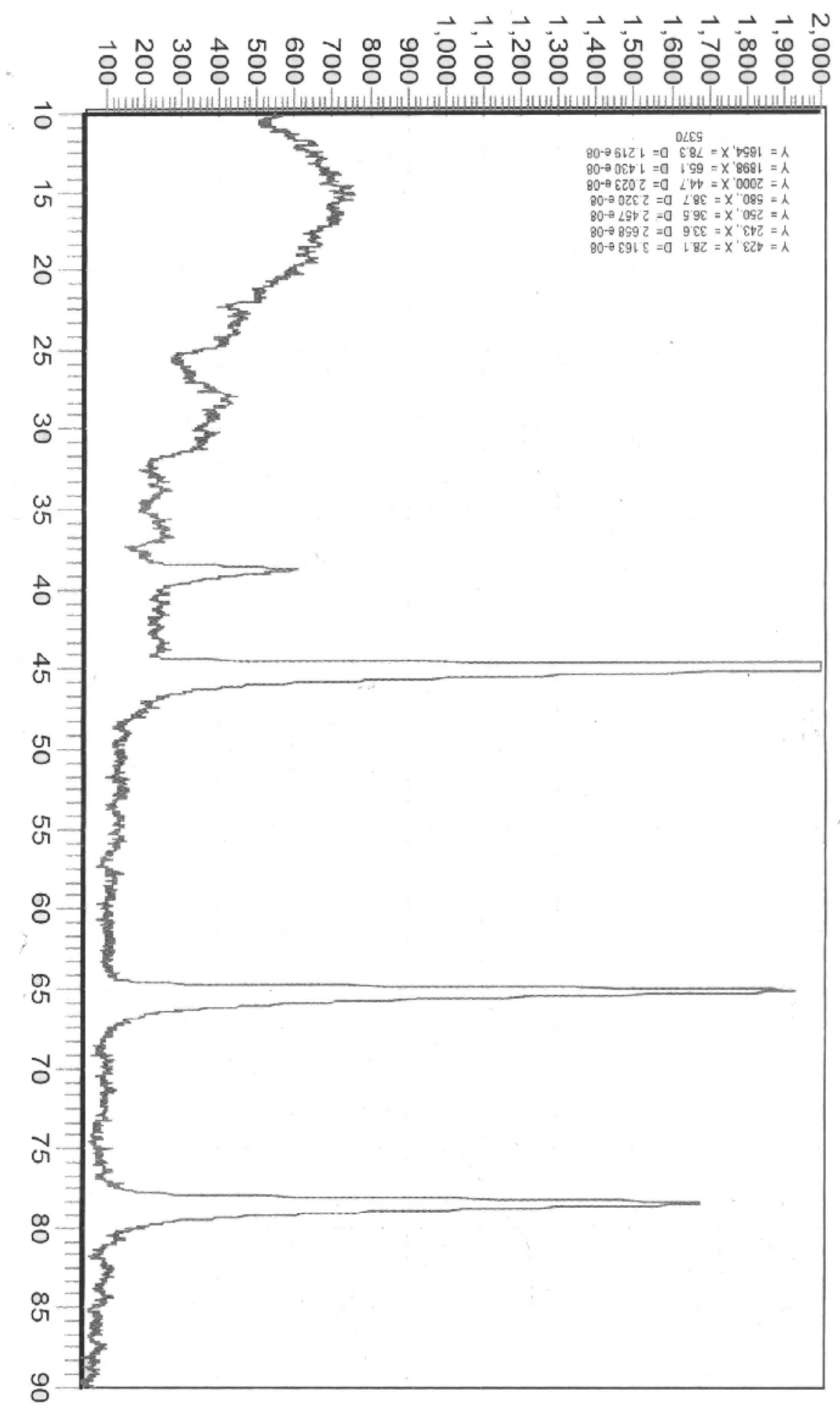


( ) مخطط حيود الأشعة السينية لسبيكة ألمنيوم - مغنسيوم 


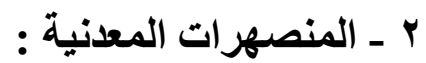

تم استخدام منصـهرين معدنير بتر اكيب مختلفة هـي الألمنيوم النقي وسبيكة الألمنيوم

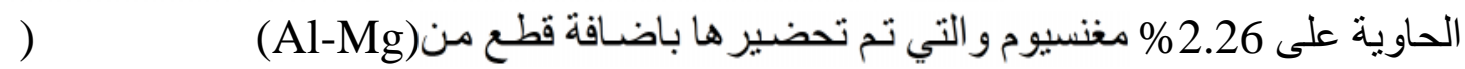

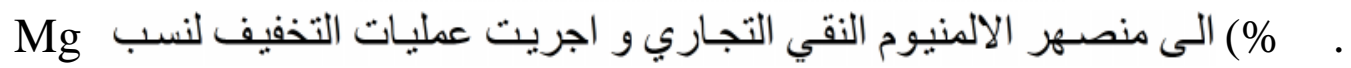

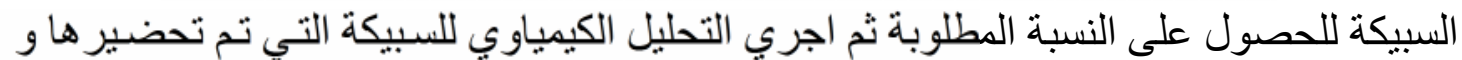

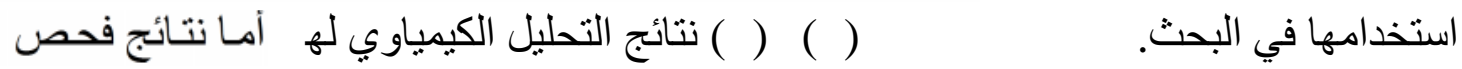

حيود الأشعة السينية فيوضحها البن الـ ( ) ( ).

الجدول ( ) التحليل الكيمياوي للألمنيوم النقي

\begin{tabular}{|c|c|c|c|c|c|}
\hline Cu \% & Fe \% & Mn \% & Si \% & Mg \% & Al \% \\
\hline 0.3062 & 0.467 & 0.028 & 0.1153 & 0.1063 & $\begin{array}{c}98.977 \\
2\end{array}$ \\
\hline
\end{tabular}

الجدول (Y) التحليل الكيمياوي لسبيكة ألمنيوم - 2.26\% مغنسيوم

\begin{tabular}{|c|c|c|c|c|c|}
\hline Si \% & Fe \% & Cu \% & Mn \% & Mg \% & Zn \% \\
\hline 0.257 & 0.215 & 0.04 & 0.0042 & 2.26 & 0.0025 \\
\hline \hline Ti \% & Cr \% & Pb \% & Ni \% & Na \% & Al \% \\
\hline 0.0041 & 0.3025 & $\mathbf{0 . 0 0 0 4}$ & $\mathbf{0 . 0 0 0 9 5}$ & $\begin{array}{c}\text { 0.0009 } \\
5\end{array}$ & 96.919 \\
\hline
\end{tabular}

تحضير النماذج السيراميكية :

تم استخدام الكبس لغرض إنتاج النماذج السير اميكية التي تمثل الأساس للمو اد المتر اكبة

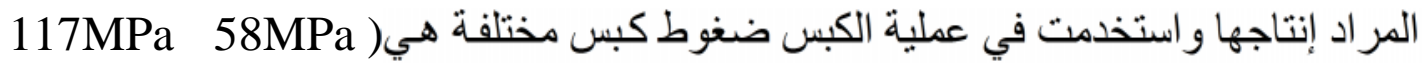
176MPa

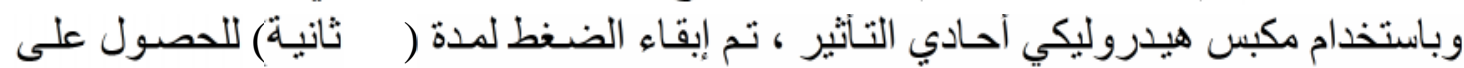

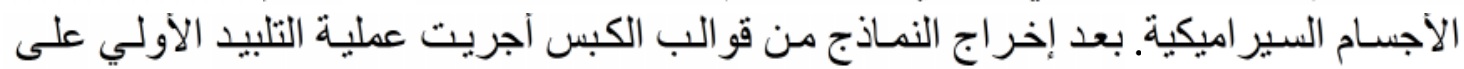

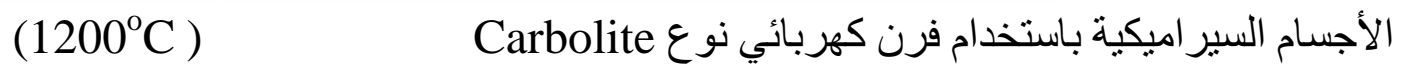
خين بمعدل

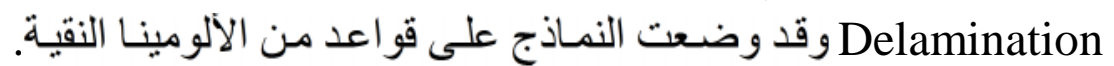

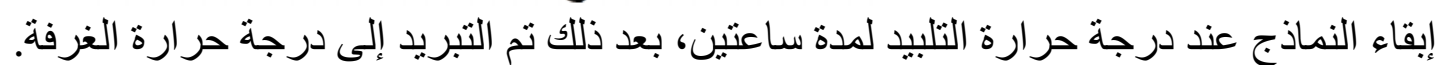




\section{حساب المسامية الظاهرية:Apparent porosity}

تعرف المسامية الظاهرية Apparent porosity بأنها

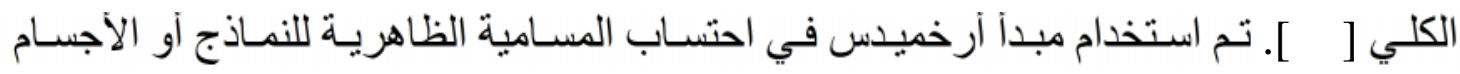

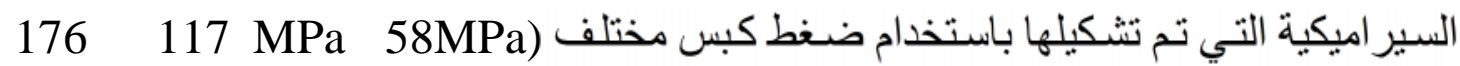
(MPa و التي أجريت عليها عليات التلبيد وتم حساب المسامية باستخدام المو اصفات القياسية

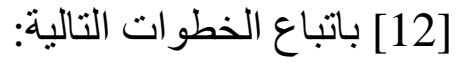

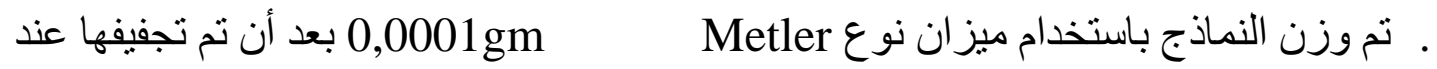

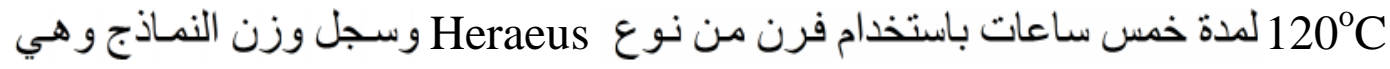

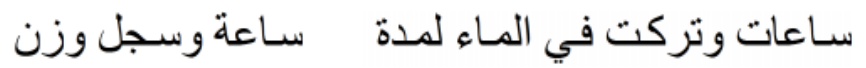

النماذج و هي موضوعة في شبكة مغورة في الماء ومعلقة فيه وسجل الوزن (I).

ـ أخرجت النماذج الملبدة من الماء ومسحت بقطعة من قماش ووزنت مرة أخرى وهي جافة (S) ونم حساب المسامية باستخدام المعادلة التالية :

Apparent Porosity $\%=\frac{S-D}{S-I} \times 100 \%$

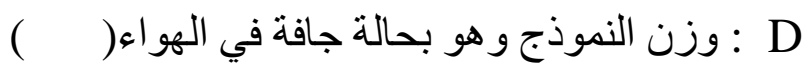

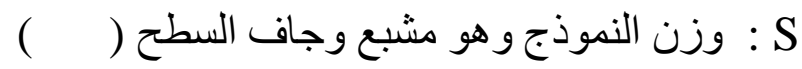

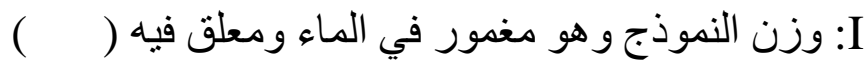

Infiltration عملية التظطيس بمنصهرات المعادن

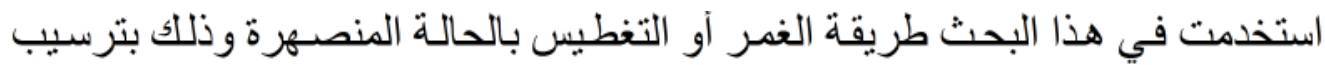

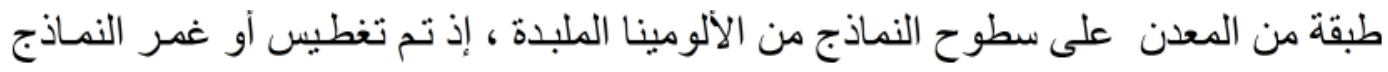

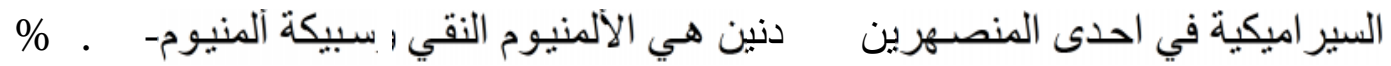

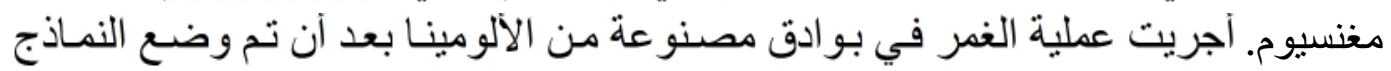

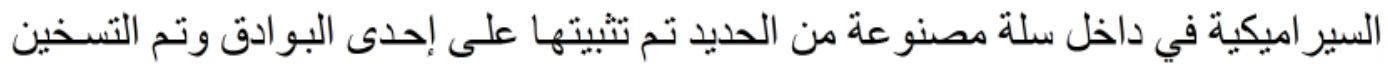

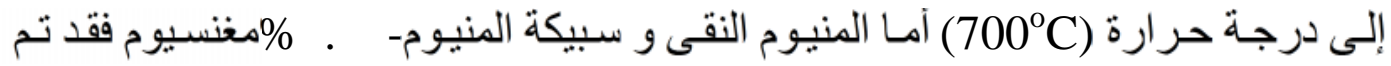




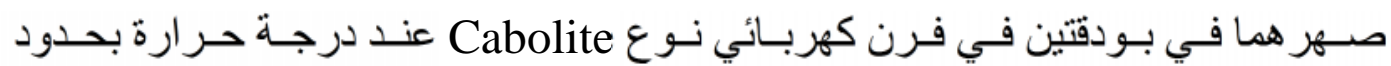

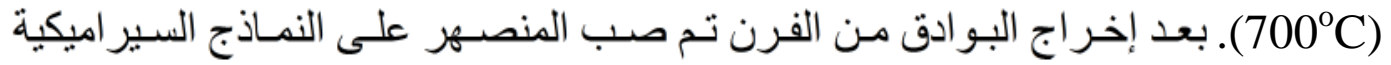

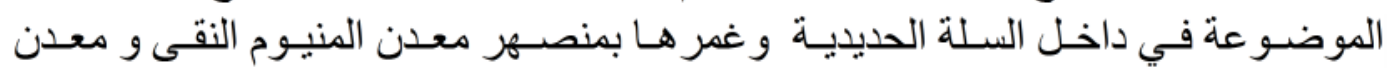

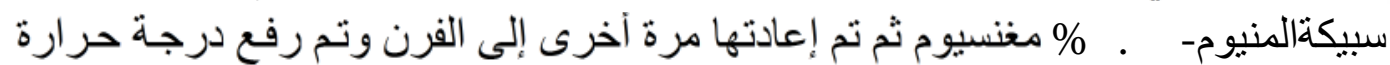

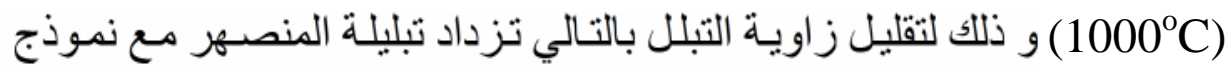

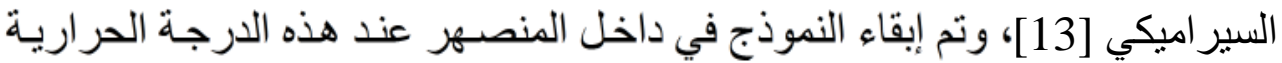

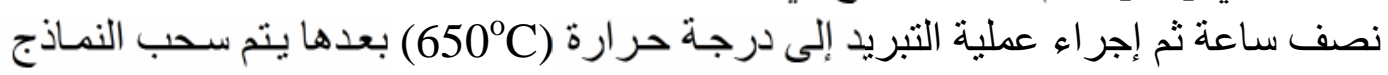
من المنصهر المعدني.

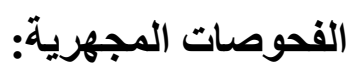

( المجهري ، الالكترونى الماسح و الفحص باستخدام حيود الاشعة فئة

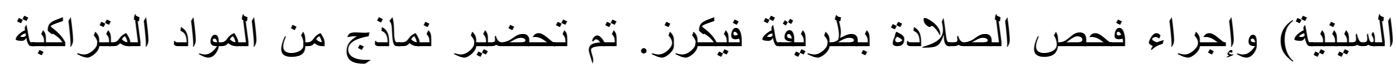

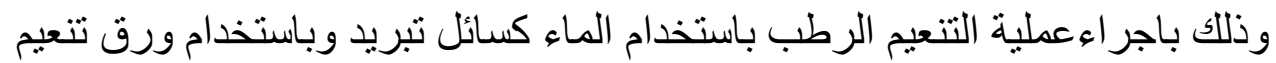

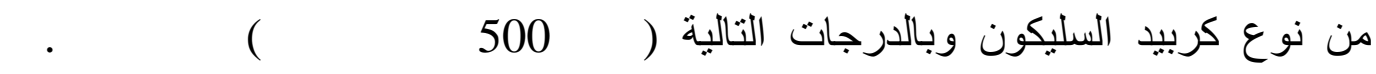
( \% م علية إظهار التراكيب المجهرية.

المجرر م Streo Scan-220 في المعرة

\section{Results and Discussion النتائج والمناقثشة}

اظهرت نتائج الفحوصات المجهرية للنماذج السير اميكية وجود طبقة معدنية بسمك جيد مترسب المبك

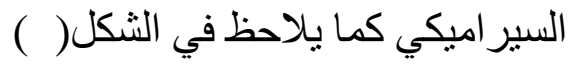

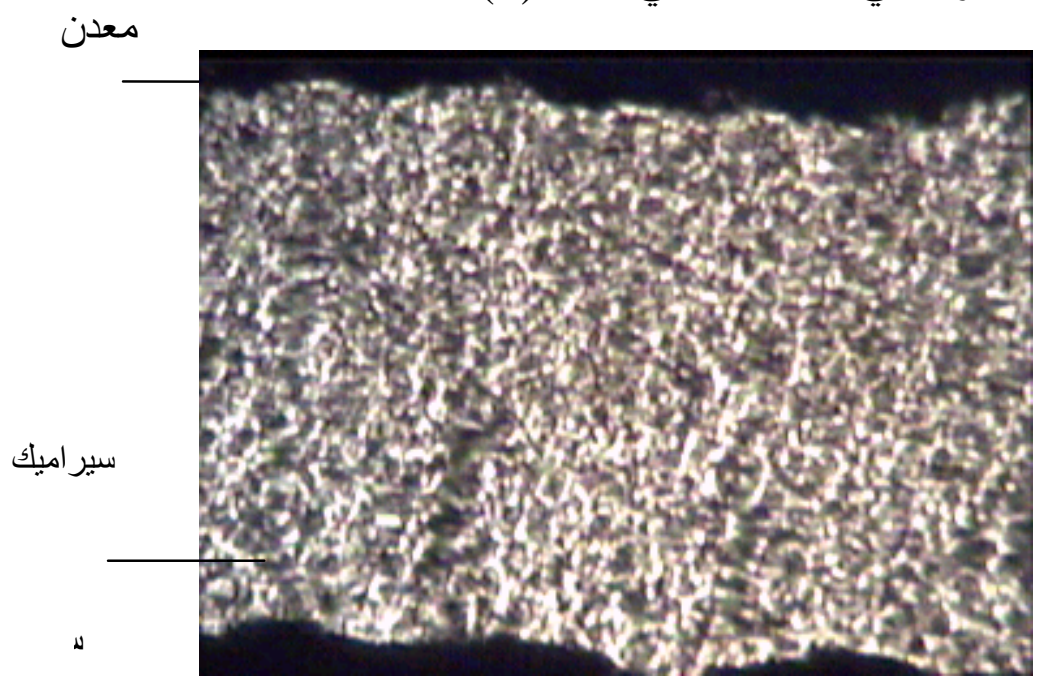


( ) التركيب المجهري للالومينا الملبد و المغمور بالالمنيوم

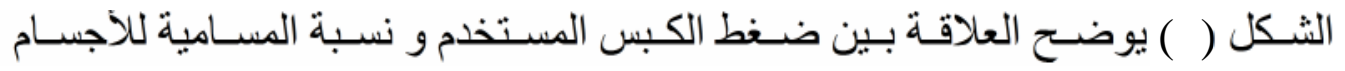

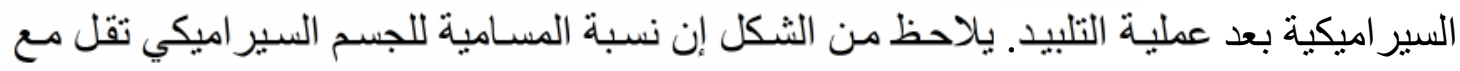

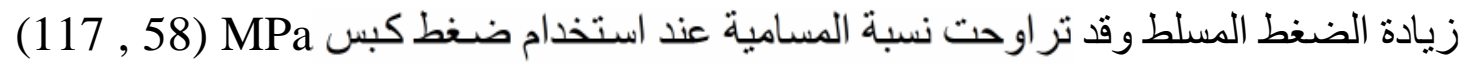

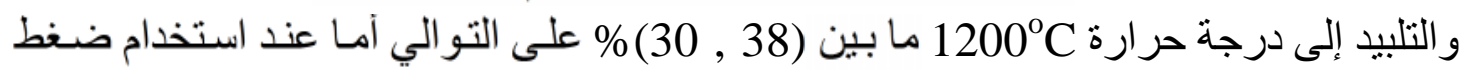
(176)MPa

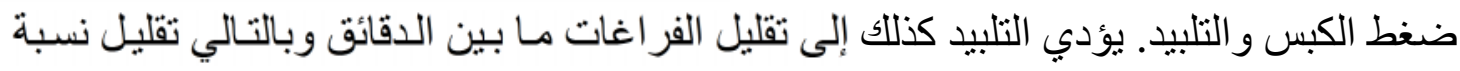

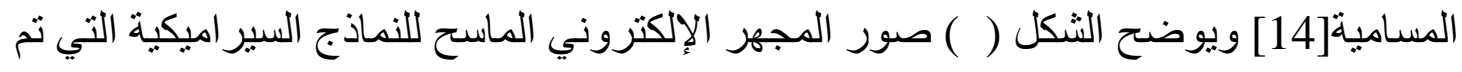

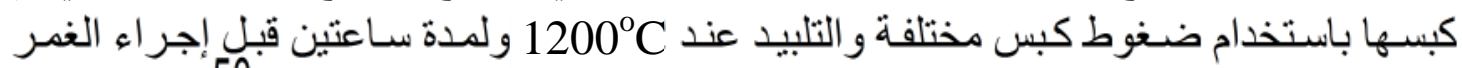

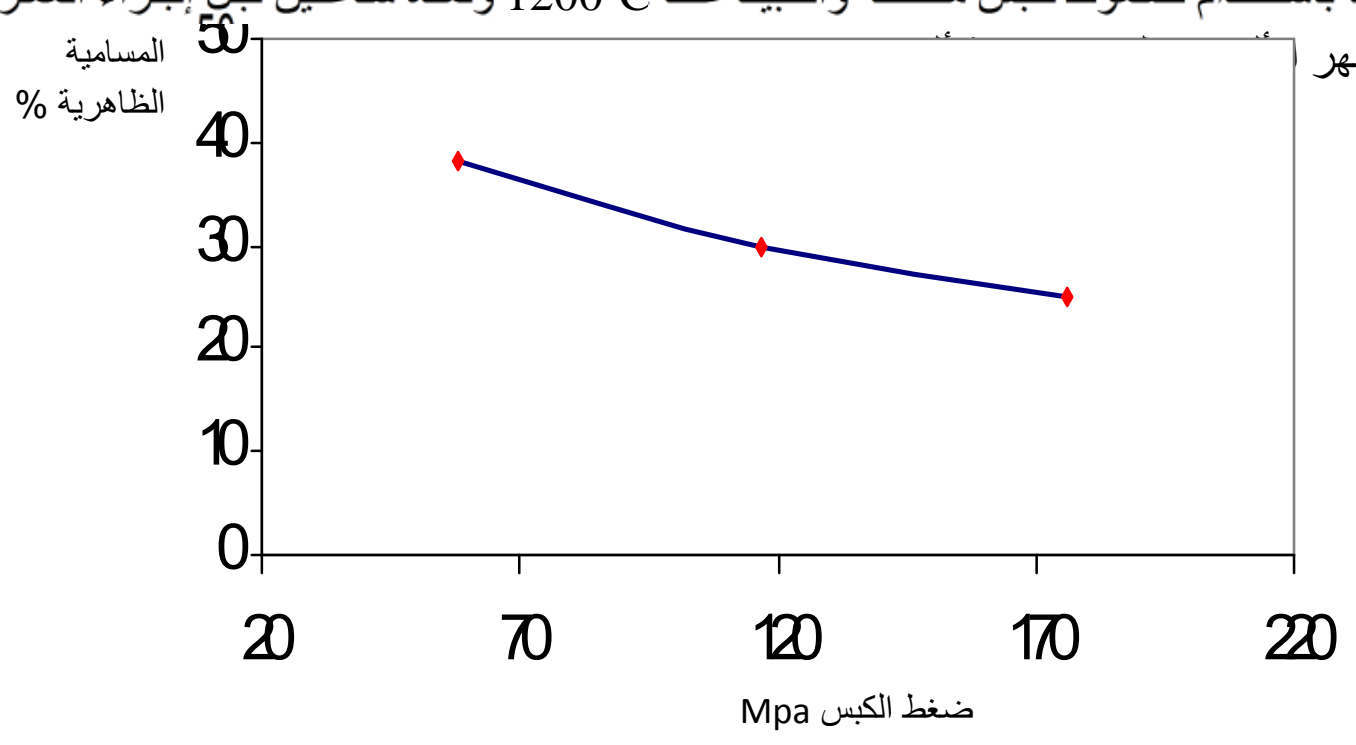


( ) العلاقة بين ضغط الكبس و المسامية الظاهرية لنماذج الالومينا الملبدة في 1200 C لمدة ساعتين
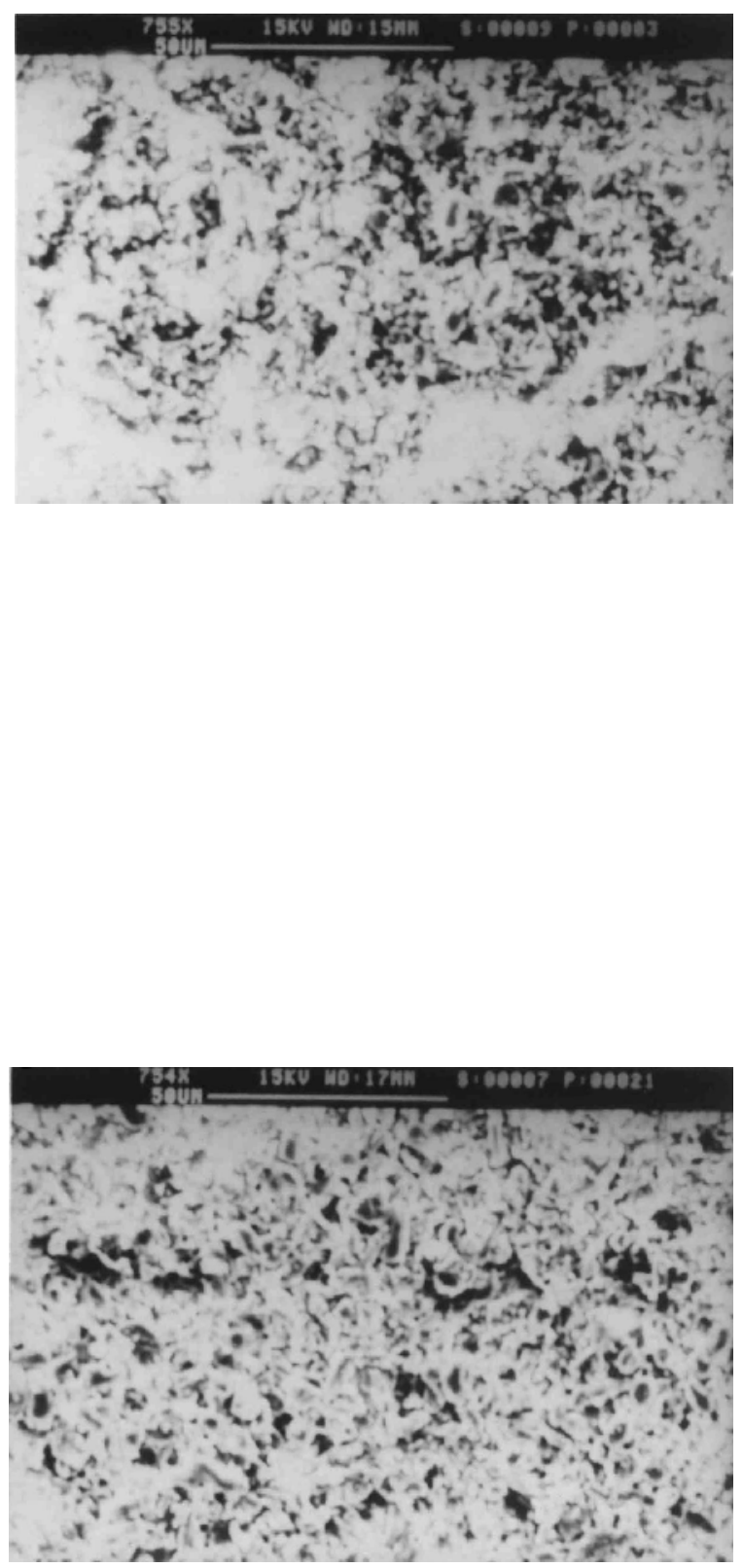


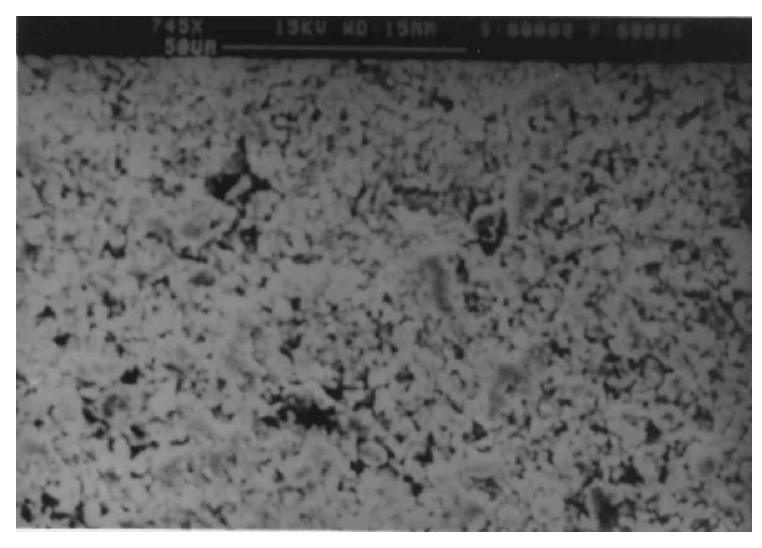

$1200^{\circ} \mathrm{C}$ ( ) ( ) مسامية النماذج السير اميكية بعد عملية التلبيد

$$
\text { \%38 - 58Ma }
$$

\% المسامية 117Mpa

\% 176MPa

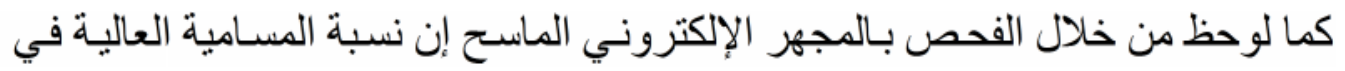

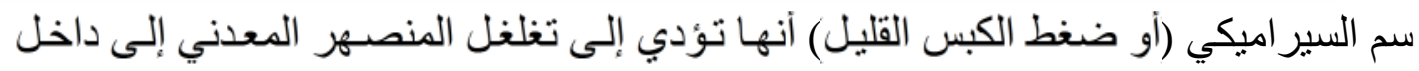

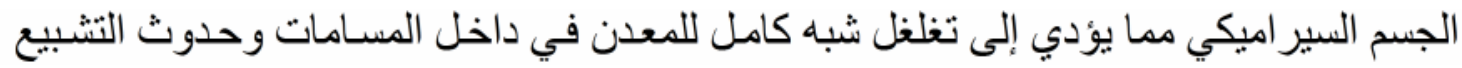

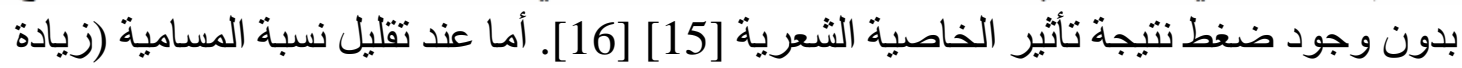

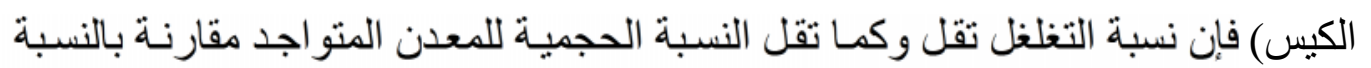

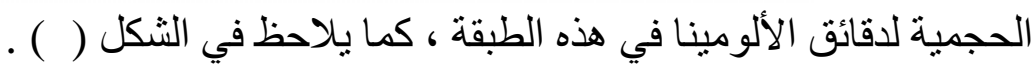

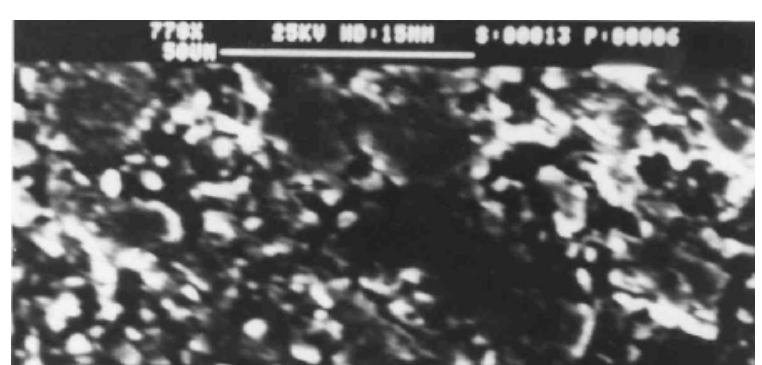


معدن

سير اميك

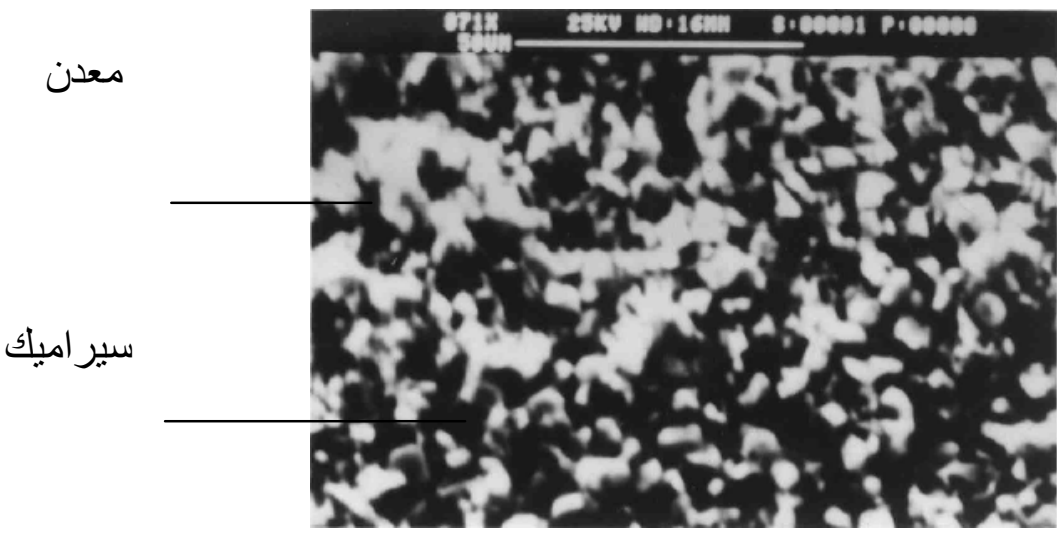

( )

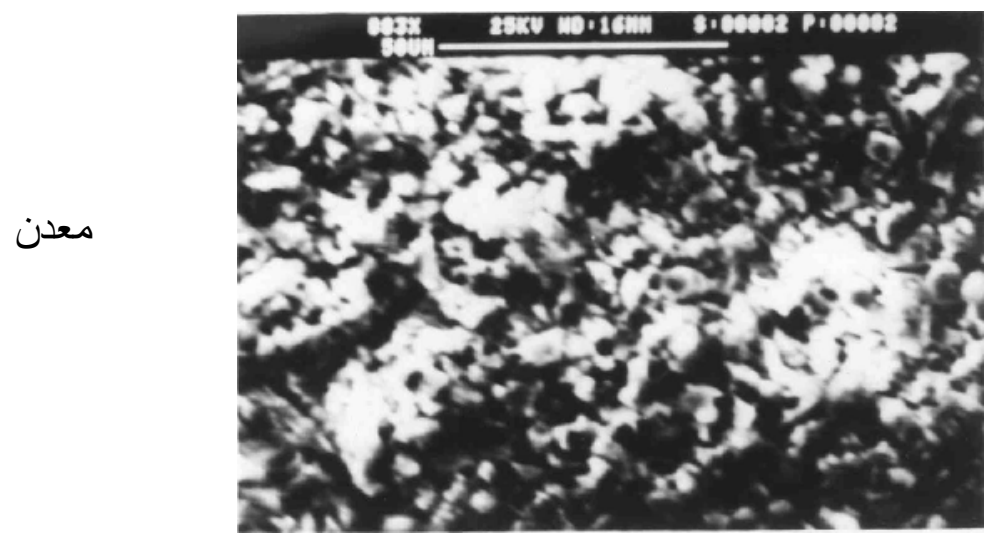




$$
\text { سير اميك }
$$

$$
\text { المعدن المنصهر في الالومينا }
$$

( ) المسامية \% \% ( ) ) المسامية

و اظهرت نتائج الفحص للنماذج المغمورة بمنصـهر سبيكة|لالمنيوم ـ مغنسيوم ظهور ثلاثة Spinel

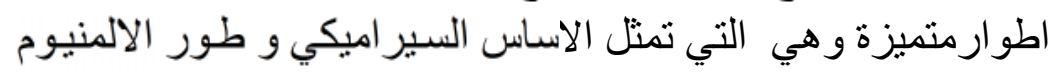

يتكون من تفاعل المغنسيو و الالمنيوم كما يوضحهي الثنكل ( ) ).

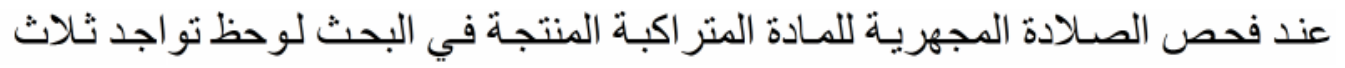

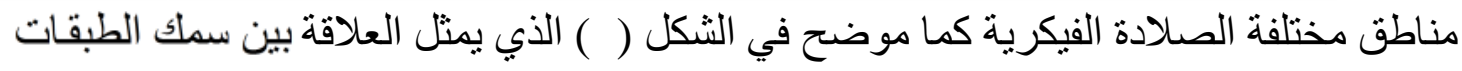

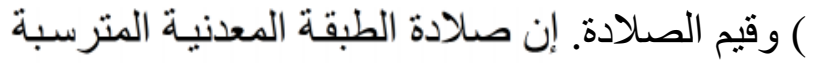

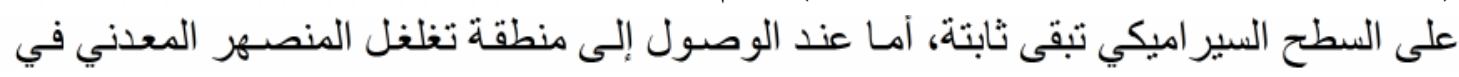




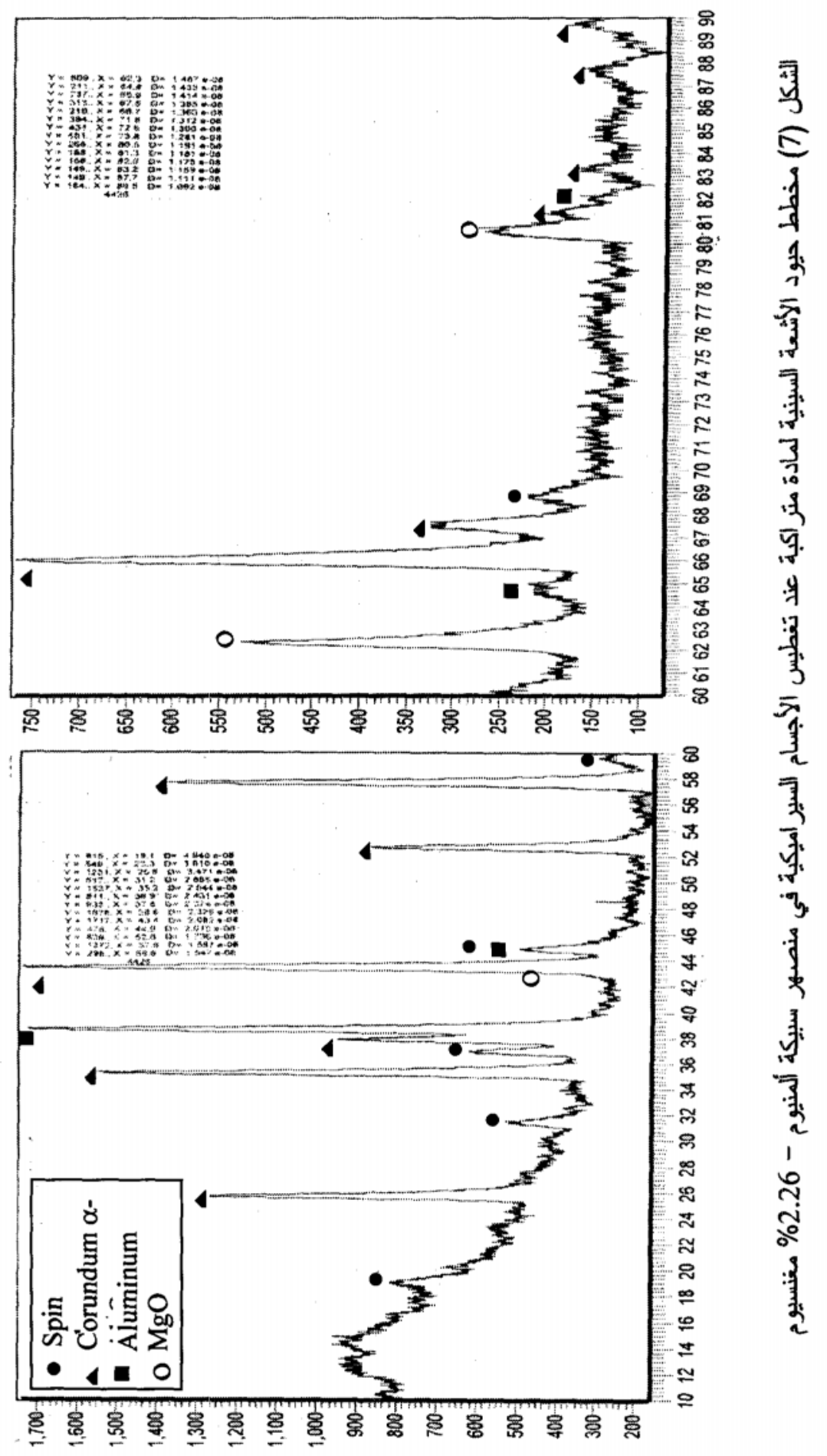


للجسـم السـير اميكي فيلاحظ زيـادة الصـلادة تـدريجياً إلى أن تصـل إلى صـلادة الأسـاس للمـادة

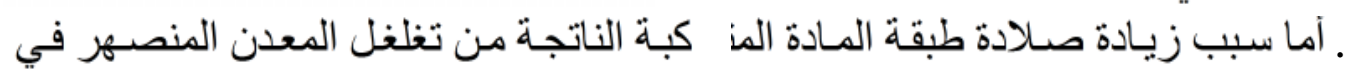

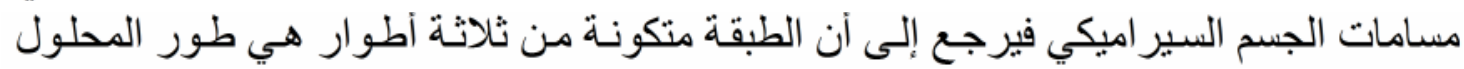
Solid Solution

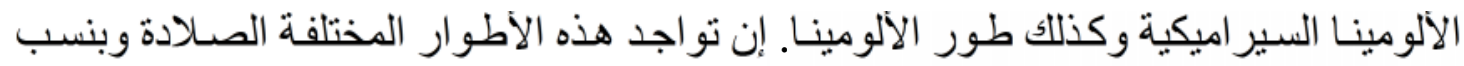

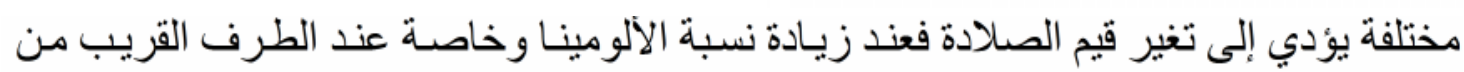

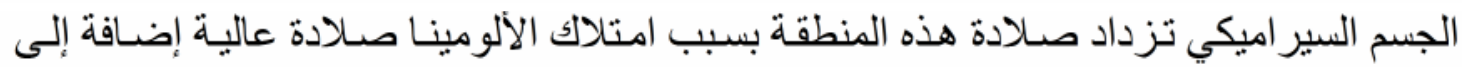
صلادة الطور الفقري الذي يتو اجد بنسب مختلفة.

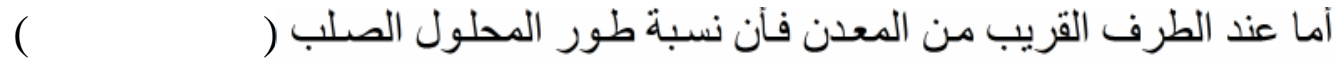

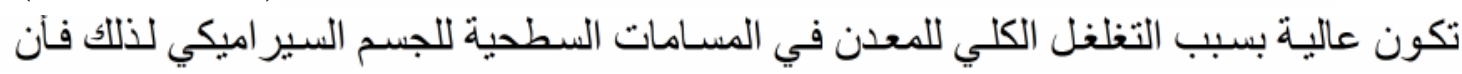

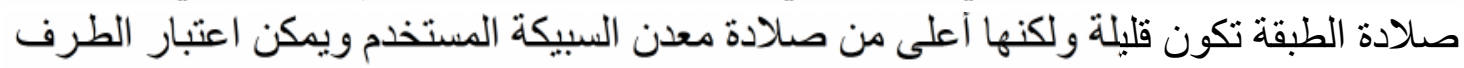

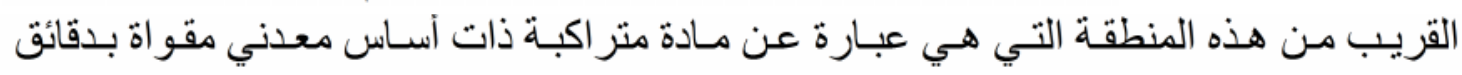

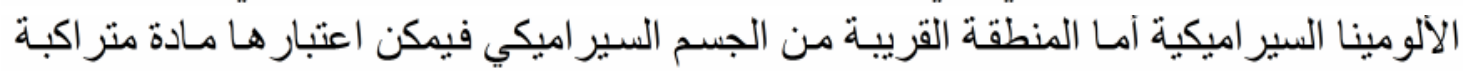

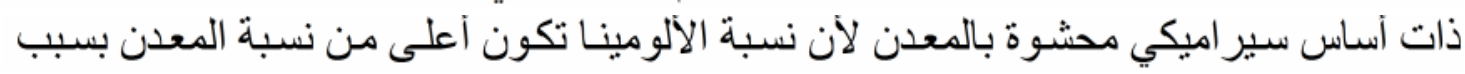

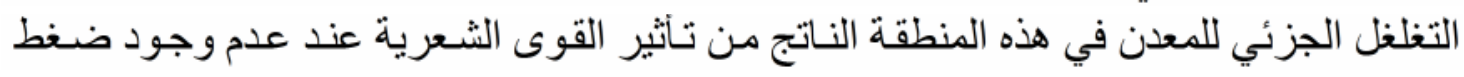

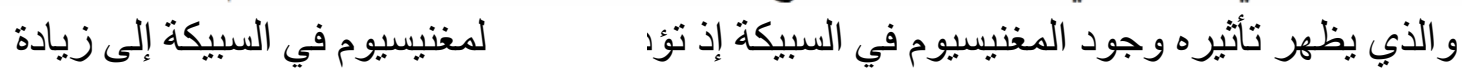

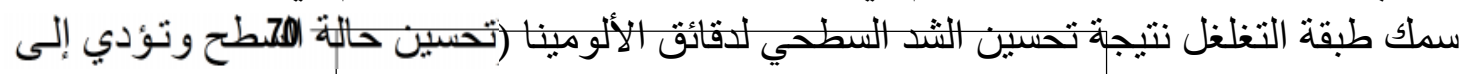

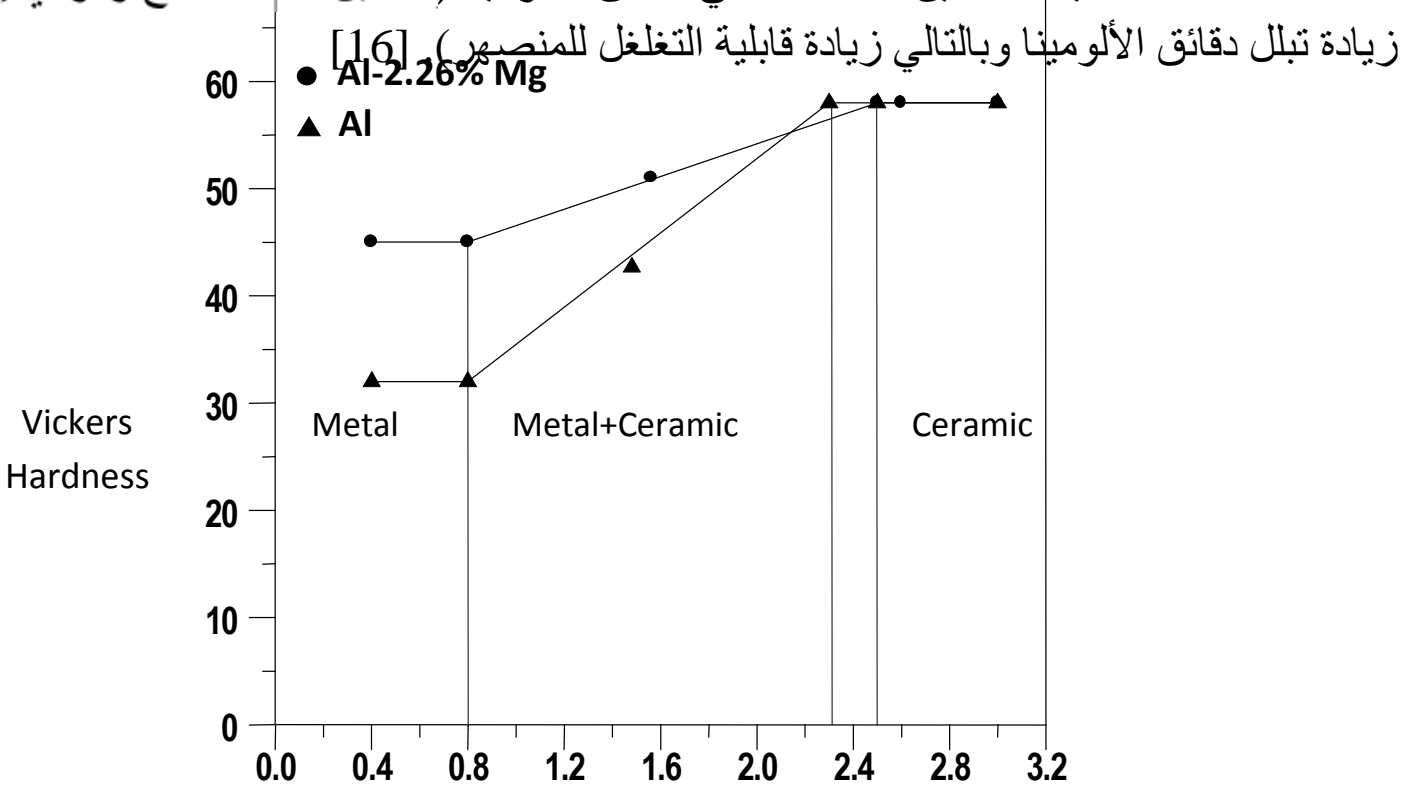




\section{Distance(mm)}

( ) العلاقة بين سمك الطبقات و الصلادة

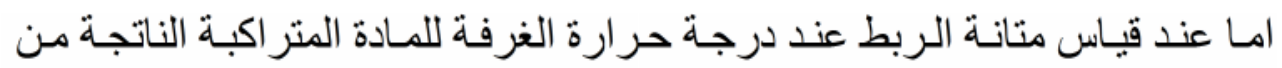

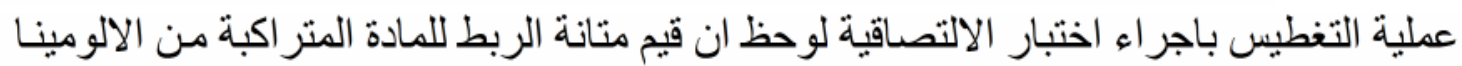

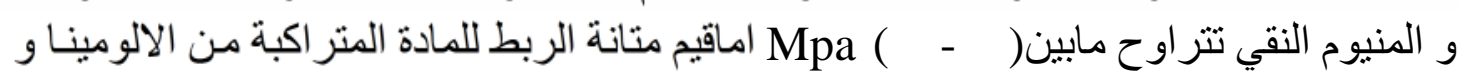

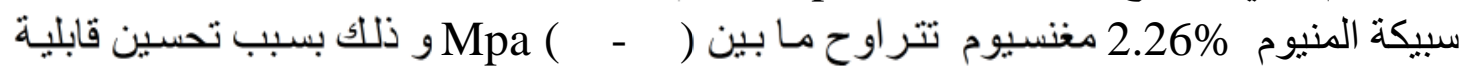

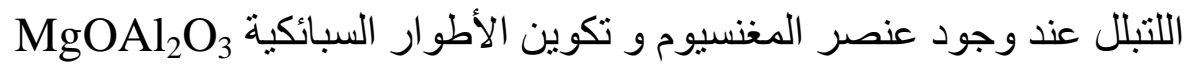

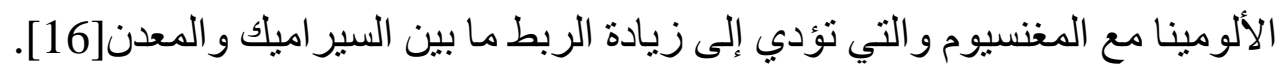




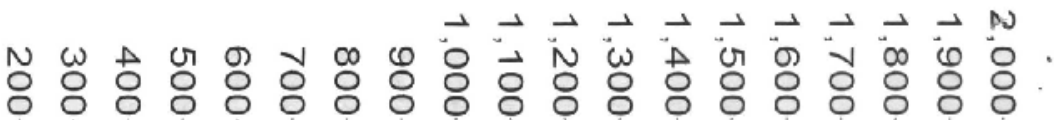

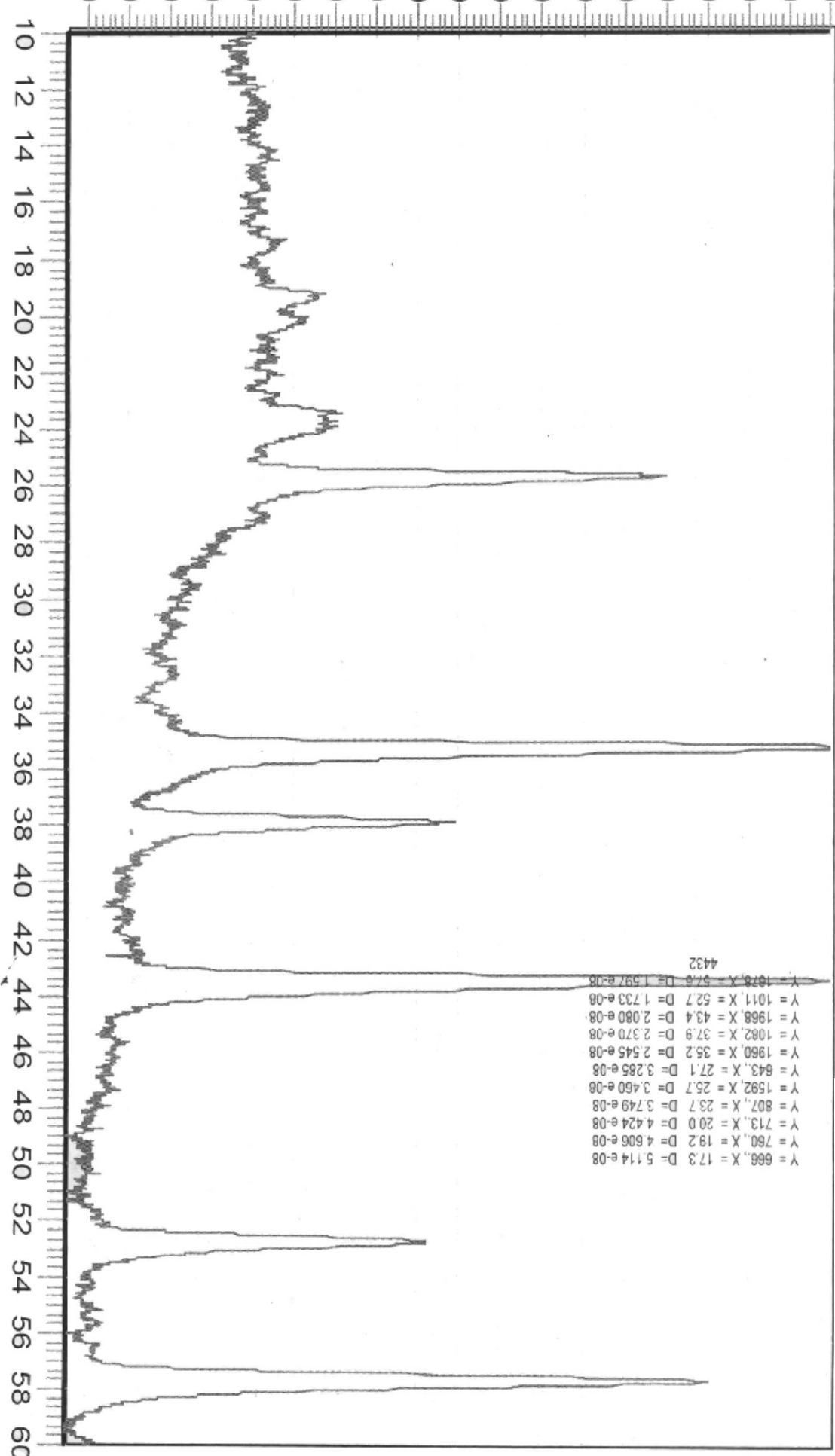




\section{الاستتناجات}

تكوين ثناث مناطق مختلفة الصلادة وذات تر اكيب و الاطو ار مختلفة هى المحلول الصلب وطور سبنل عند غمر النموذج السير اميكي بمنصهر المعادن. تزداد تبليلية النموذج السير اميكي بمنصهر الالمنيوم عندوجود عنصر المغنسيوم. تزداد التر ابط بين النموذج السير اميكي و الالمنيوم عند تكوين طور سبنل. 


\section{Refrences}

[1] Askeland R.D. and Phule P.R. , "The Science and Engineering of Material", $4^{\text {th }}$ edition, PP.721,USA, 2003.

[2] Meyers M. A. an Chawla K.K. , "Mechanical Behavior of Materials" Hall, 1999.

[3] Bolten W., "Engineering Materials Technology", $3{ }^{\text {rd }}$ Edition, Reed Education \& Professional Publishing Ltd., 1998.

[4] Smallman R. E. and Bishop R. J., "Modern Physical Metallurgy and Materials Engineering”, Reed Education Publishing Ltd., 1999.

[5] Thoreton D. A. and Colangclo V., "Fundamental of Engineering Material", 1st Edition A Wiley-Interscience Publication, 1985.

[6] Shen Y. L., "Thermal Expansion of Metal - Ceramic Composites: A 3- Dimensional Analysis", Materials Science and Engineering, Vol. A 252,PP. 269 - 275, 1998.

[7] Lwis M.H., "Ceramic to Be Joined 10 Years From Now”,Designing Interfaces Elsevier Applied Science, 1989.

[8] Cawley J. D., "Joining of Ceramic - Matrix composites", Ceramic Bulletin, Vo1. 68, No.9, PP.1619-1622,1989.

[9] Dalgleish B. J. etal., "The Strength of Fracture of $\mathrm{Al}_{2} \mathrm{O}_{3}$ Bond With Al Aalloys", Acta. Metal., Vo1.37, No.7, PP.1923 - 1931, 1989.

[10] Rohatgi P.K. etal., "Pressure Infiltration Technique for Synthesis of Aluminum-Fly Ash Particulate Composite", Materials Science and Engineering, Vol. A 244,( 1998)22-30.

[11] Ryan W. and Radford C., "White Wares: Production, Testing and Quality Control", Pergamon Press, PP.224-232, 1987.

[12] ASTM Standard No.:C373, 1987 
[13] Laurent V. etal., "Wettability of Monocrystalline Alumina by $\mathrm{Al}$ Between Its Melting Point and $1000^{\circ} \mathrm{C}$ ", Acta. Metall., Vo1.36, No.7, PP.1797-1803, 1988.

[14] Shaw N. J., "Densification and Coarsining During Solid State Sintering of Ceramics", P.M.I. Vol.21, No.3,PP.6-20, 1989

[15] OH S.Y. etal., "Wetting of Ceramic Particulate With Liquid Al Alloys Part I " Mettallurgical Transactions, Vo1.20A, PP.533-541, March 1989.

[16] OH S.Y etal., "Wetting Ceramic Particulate With Al Liquid Alloys Part I Experimental Techniques", Metallurgical Transactions , Vo1.20A, PP.527-532, March 1989.

$$
\text { تم اجراء البحث في المعهـ الفني - اربيل }
$$

